\title{
硫黄充填反応槽を用いた嫌気性処理後の 畜舎污水の窒素除去と脱色
}

\author{
Decoloration and Nitrogen Removal of Swine Wastewater \\ After Anaerobic Treatment Using the Sulfur Filling Up Reactor
}

陳 昌淑、田中康男

農業技術研究機構畜産草地研究所資源化研究室 / $305-0901$ 茨城県稲敷郡茎崎町池の台2

CHANG-SUK JIN, YASUO TANAKA

Waste Recycling Lab., Dept. of Livestock Industry Environment, National Institute of Livestock and Grassland Science/2 Ikenodai, Kukisaki-cho, Inashiki-gun, Ibaraki 305-0901, Japan

\begin{abstract}
An innovative upflow sulfur filling up reactor was developed to remove nitrogen of swine wastewater after anaerobic treatment. This reactor consisted of a high DO upper layer filled with polyester unwoven cloth media and a low DO lower layer filled with sulfur pellet containing calcium $\left(\mathrm{S}^{\mathrm{o}}+\mathrm{CaCO}_{3}\right.$ pellet). Anaerobically treated swine wastewater was supplied to the reactor from the middle layer. Overflow from the top of the reactor was partially recirculated to the bottom of the reactor, and the remainder was finally fed to a gravity settling tank. Removal efficiencies of $\mathrm{NH}_{4}{ }^{+}-\mathrm{N}$ and $\mathrm{T}-\mathrm{N}$ were affected by the circulation ratio, and maximum removal $\left(63 \%\right.$ for $\mathrm{NH}_{4}{ }^{+}-\mathrm{N}, 42 \%$ for T-N) was observed at a circulation of 2. Accumulation of $\mathrm{NO}_{2}^{-}-\mathrm{N}$ was observed at a circulation ratio of more than 2, but no accumulation of $\mathrm{NO}_{3}^{-}-\mathrm{N}$ was observed at any circulation ratio. Free ammonia concentration in influent and effluent was estimated to range from 4.9 to $100 \mathrm{mg} / l$ (average : $34.9 \mathrm{mg} / l$ ). Free ammonia would inhibit oxidation of $\mathrm{NO}_{2}{ }^{-} \mathrm{N}$. On the other hand, free nitrous acid was less than $0.2 \mathrm{mg} / l$, and it was not inhibited oxidation of $\mathrm{NO}_{2}^{-} \cdot \mathrm{N}$.

The effluent $\mathrm{SO}_{4}{ }^{2-}-\mathrm{S}$ concentration correlated with the decoloration rate $(\mathrm{r}=0.757)$, suggesting a relationship between sulfur oxidation and color removal.
\end{abstract}

Key Words : swine wastewater, sulfur oxidation reaction, decoloration, nitrification, denitrification

\section{1.はじめに}

豚舎からの排水は、窒素濃度が非常に高く除去が困難 といった問題を抱えている ${ }^{1}$ 。窒素除去法としては硝 化・脱窒による生物学的方法が最も実用的であるが、既 存の硝化工程ではアンモニア $\left(\mathrm{NH}_{3}\right)$ を硝酸 $\left(\mathrm{NO}_{3}\right)$ まで 酸化するための酸素供給に多くのエネルギーを要する。
硝化に必要な酸素を供給するためのエネルギーを低減す るためには硝化を亜硝酸 $\left(\mathrm{NO}_{2}\right)$ で停止させ亜硝酸から 脱窒されるようにすることも効果がある2.31。そのために は、亜硝酸酸化反応を抑制し亜硝酸を蓄積させることが 必要である。亜硝酸酸化反応に影響を及ぼす因子として は遊離アンモニア（FA, Free Ammonia, $\mathrm{NH}_{3}$ ) 濃度、遊 離車硝酸（FNA, Free Nitrous acid, $\mathrm{HNO}_{2}$ ) 濃度、温度、 
$\mathrm{pH} 、 \mathrm{SRT}$ などがあり、特に大きな影響を与えているのは FA濃度である4”FA濃度が0.1-10mg/lの範囲では、ア ンモニアから亜硝酸までの反応は進むが、亜硝酸から硝 酸までの反応は抑制される ${ }^{4}$ 。音舎污水は高濃度のアン モニアを含んでいるので、何らかの方法で高い $\mathrm{pH}$ を保て ばFA濃度が高くなり、亜硝酸酸化反応を抑制できる可能 性がある。

しかしながら、音舎污水の場合 $\mathrm{C} / \mathrm{N}$ 比が低い場合が多 く硝化までは進行したとしても脱窒が不充分になる場合 が多い。特に嫌気性処理を導入した場合には $\mathrm{C} / \mathrm{N}$ 比が低 下するため脱窒はさらに不利となる。脱窒のための電子 供与体としてメタノールを添加する方法もあるが適切な 注入量の制御が困難でしかも毒性があるため処理水に残 存すると問題になる。硫黄酸化脱窒菌は、無酸素状態で 還元硫黄化合物 $\left(\mathrm{S}^{0}, \mathrm{~S}^{2-}, \mathrm{S}_{2} \mathrm{O}_{3}{ }^{2-}, \mathrm{S}_{4} \mathrm{O}_{6}{ }^{2-}, \mathrm{SO}_{3}{ }^{2-}\right)$ を硫酸 イオン $\left(\mathrm{SO}_{4}{ }^{2-}\right)$ に酸化する際に、硝酸性窒素 $\left(\mathrm{NO}_{3}{ }^{-}{ }^{-} \mathrm{N}\right)$ または亜硝酸性窒素 $\left(\mathrm{NO}_{2}{ }^{-}-\mathrm{N}\right)$ を窒素ガス $\left(\mathrm{N}_{2}\right)$ に脱窒 することから、低 $\mathrm{C} / \mathrm{N}$ 比の排水を生物学的に脱窒処理す るとき、有機炭素源のかわりに硫黄を利用する技術が検 討されている ${ }^{5}$ 。しかし、硫黄酸化反応で $\mathrm{SO}_{4}{ }^{2-}$ が生成す ると $\mathrm{pH}$ が下がり FA濃度が下がるので亜硝酸酸化抑制の 面では不利となる。 $\mathrm{pH}$ 高く保つには炭酸カルシウム $\left(\mathrm{CaCO}_{3}\right)$ などの添加が効率的であるが、硫黄と $\mathrm{CaCO}_{3}$ を 別々に添加しようとすると適切な添加量の調整が難しい。 この点を克服する素材として硫黄と炭酸カルシウムがパ ッチ状になるように混合し造粒された材料 $\left(\mathrm{S}^{\circ}+\mathrm{CaCO}_{3}\right.$ pellet $\left.^{6}\right)$ ) が開発されており、その適用が効果的である可 能性がある。

また畜舎污水は、様々な処理により污濁成分を排水基 準まで除去しても、茶褐色の着色が除去できない場合が 多ぐ.8、放流の際に問題となることが多い。最近、排水 の色に関する関心が高くなり規制を強化しようとする動 きがあり ${ }^{9}$ 、畜舎污水の脱色処理についても今後重要性 を増してくる可能性が高い。現在の脱色処理技術として は、凝集郕を用いる凝集沈殿法、活性炭を用いる吸着法、 オン゙ン・フェントン反応・電気分解などによる酸化法な どがある。しかし、凝集沈殿法は凝集沈殿物が生成され るのでその沈殿物を処理することが必要となる。また活 性炭吸着法は活性炭の吸着能の限界を超えると、活性炭 交換と使用済み活性炭の廃棄問題が生じる。さらに酸化 法は処理コストが高いという問題を抱えている ${ }^{7-10}$ 。

本研究では、1槽で亜硝酸までの硝化と硫黄による脱 窒を目指して、上部には好気ゾーン、下部には $\mathrm{S}^{0}+$ $\mathrm{CaCO}_{3}$ pelletを充填した無酸素ゾーンを設けた反応槽を
用いて、嫌気性処理後の畜舎污水処理を処理特性に強く 影響する可能性がある循環比に焦点を置いて検討した。 また、脱色の可能性についても検討した。

\section{2. 実検方法及び材料}

\section{1 実験装置}

1 槽で亜硝酸までの硝化と硫黄による脱窒を効率良く 行わせることを目指して、2 種のプラスチックろ材と $\mathrm{S}^{\mathrm{o}}$ $+\mathrm{CaCO}_{3}$ pelletを充桭した反応槽を考案した。反応槽の 有効総容量は28lであり、反応槽の上部にはポリエステル の編みチューブと不織布の外層フィルターで構成された 固定万材 (見かけ容量 $: 10 l$ )、最下部には $2 \mathrm{~kg} の \mathrm{~S}^{0}+$ $\mathrm{CaCO}_{3}$ pellet $($ 粒径 $5-20 \mathrm{~mm}$ 、見かけ容量 : $5 \mathrm{l}$ )、また中 間には反応槽上部の $\mathrm{DO} か ゙ \mathrm{~S}^{0}+\mathrm{CaCO}_{3}$ pellet層に拡散す ることを防ぐため 1 片 3-5 cmのサイコロ状のポリウレ タンフォームの浮遊性ろ材 (見かけ容量 $: 10 l$ ) を配置し た。不織布の固定ろ材層の直下に散気管を設置し、散気 管の下から原水を流入させた。通気量は $10 \mathrm{l} / \mathrm{min}$ であっ た。処理水は上部の流出口から沈澱槽に入るが、この間 に循環経路を設け、循環水は反応槽の最下部から流入さ せた (Fig. 1)。反応槽内の水温はテープヒーターを利用 して20ㄷを保つようにした。運転はHRTを2.16日（流入 排水量 : $0.54 \mathrm{l} / \mathrm{hr}$ ) に固定して循環比を $0,1,2,4$, 8 に変えながら行った。

\section{2 原水}

原水としては豚舎污水をHRT 2 日のUASBリアクター で嫌気性処理したものを用いた。

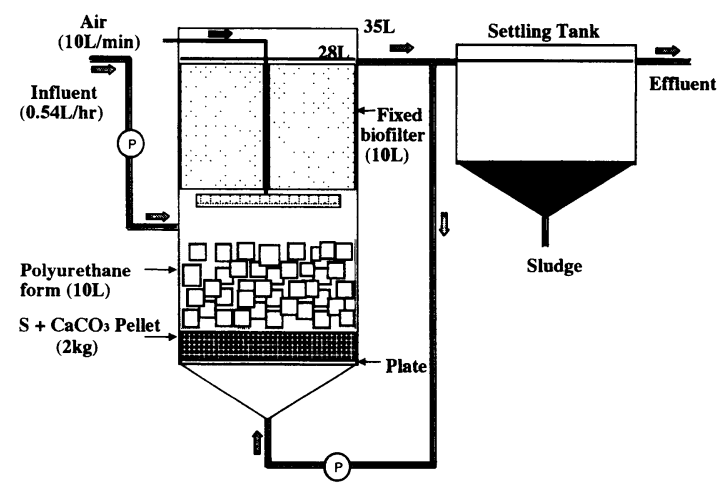

Fig. 1 Flowsheet of experimental apparatus. 


\section{3 植種源}

反応槽への微生物の植種には以下の方法で培養した污 泥を用いた。畜舎污水処理施設の活性污泥 (MLSS : 約 $6,000 \mathrm{mg} / l)$ を $\mathrm{NH}_{4} \mathrm{Cl} 3.5 \mathrm{~g}, \mathrm{NaHCO}_{3} 10.5 \mathrm{~g}$ ，およびBOD 希釈水 $1 l\left(\mathrm{MgSO}_{4} 1 \mathrm{ml}, \mathrm{FeCl}_{2} 1 \mathrm{ml}, \mathrm{CaCl}_{2} 1 \mathrm{ml}, \mathrm{H}_{3} \mathrm{PO}_{4}\right.$ $1 \mathrm{~m} l$, 水道水 $1 l)$ 加なる硝化菌培養培地 ${ }^{11}$ に懸濁さ せ、DO濃度約 $3 \mathrm{mg} / l$ を維持するように曝気した。1日 1 回、30分間沈殿させてから $1 / 2$ の上澄みを捨て同量 の新しい培地を添加した。 $\mathrm{pH}$ は8.0-8.5、水温は約 $20^{\circ} \mathrm{C}$ に維持した。約 2 力月間馴養させた後、不織布ろ材に付 着させた。

\section{4 分析方法}

BODはHACH社のBOD TRACK自動測定器を用いて 5 日法により、CODcr は HACH社の重クロム酸法 $\mathrm{COD}$ 測定 システム（DR/700 Colorimeter \& COD Reactor）を用い て測定した。全窒素（T-N）と全リン（T-P）はサヌキ 工業製フローインジェクション分析装置 $(\mathrm{T}-\mathrm{N} / \mathrm{T}-\mathrm{P}$ 計) を用いて測定した。この装置において $\mathrm{T}-\mathrm{N} は 1400^{\circ} \mathrm{C}$ 過硫 酸カリウム分解の後塩酸酸性下での吸光度により、また $\mathrm{T}-\mathrm{P}$ は $140^{\circ} \mathrm{C}$ 過硫酸カリウム分解の後モリブデンブルー 法による880nm吸光度測定により定量される。 $\mathrm{NH}_{4}{ }^{+}-\mathrm{N}$ は フローインジェクション法 (Aquatec 5400 Analyzer, Foss Tecator, AQUATEC社）によって測定した。T-N、 $\mathrm{T}-\mathrm{P} 、 \mathrm{NH}_{4}{ }^{+}-\mathrm{N}$ は懸濁物（SS）を含んでいる原液を50倍 に希釈して分析した。 $\mathrm{NO}_{2}{ }^{-}-\mathrm{N} 、 \mathrm{NO}_{3}{ }^{-}-\mathrm{N} 、 \mathrm{PO}_{4}{ }^{2-}-\mathrm{P} 、 そ$ して $\mathrm{SO}_{4}{ }^{2-}-\mathrm{S}$ は試料を50倍に希釈しミリポア $\mathrm{HA}$ フィル ターでろ過してからイオンクロマトグラフィー（IC 7000, Yokogawa社) で分析した。着色度は15000rpm、5 分間遠心分離してSSを除去した後、着色度計 (NDR2000 , 日本電色工業社）を用いて分析した。この機器は 「希釈法一XYZ濃度和検量線」を使用する方法で着色度を

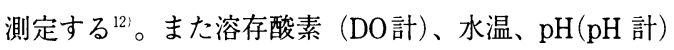
も測定した。

\section{3. 実験結果及び考察}

\section{1 原水の性状}

UASB処理前の豚舎污水と実験の原水として用いた UASB処理水の性状をTable 1 に示した。污水とUASB処 理水を比べると、平均的にBOD 93\%、CODcr $87 \% 、 \mathrm{~T}-$ $\mathrm{N} 11 \% 、 \mathrm{~T}-\mathrm{P} 73 \%$ の低下が見られた。流入水の $\mathrm{NH}_{4}{ }^{+}-\mathrm{N}$ はT-Nの約 $88 \%$ 占めており、BOD/T-NはO $46 、 \mathrm{CODc}_{\mathrm{r}}$
/T-Nは1.9と非常に低い。BOD/T-Nが3 以上でないと 脱窒が充分に進行しない: ということから考えると、こ の值はかなり低く、電子供与体の添加無しでは充分な脱 窒は期待できない。着色度は流入水の平均值が 2455 で濃 い茶褐色であった。

\section{2 反応槽内のDO濃度の分布}

本法において反応槽内のDO濃度の制御は重要である。 下部の無酸素ゾーンのDO濃度が高くなると硫黄による 脱窒効果は減少するからである。

循環比別に測定したDOの垂直分布の結果によると、 散気管より上部 $(43 \mathrm{~cm}$ 以上) では $2-6 \mathrm{mg} / l$ 以上の DO が測定されたが、散気管より下部 $(43 \mathrm{~cm}$ 以下) ではDO が急激に激少し $30 \mathrm{~cm}$ では1.3-2.7mg/lの低い值を示し た。なお、 $\mathrm{S}^{0}+\mathrm{CaCO}_{3}$ pellet層直上位置 $(13 \mathrm{~cm})$ のDO は、循環比 8 で $0.9 \mathrm{mg} / l \sim 1.5 \mathrm{mg} / l$ 、循環比 4 で $0.9 \mathrm{mg}$ $/ l$ 、循環比 2 では $0.4 \mathrm{mg} / l \sim 0.6 \mathrm{mg} / l$ で、循環比の高い ほど上昇する傾向が見られた。この結果から反応槽の中 間部分から通気することで、上下部のDO濃度をある程 度制御できることが確認された。反応槽をさらに高くす れば、ポリウレタンフォームの浮遊性ろ材を設置しなく でもより確実に上下部の状態が分かれると考えられる。

\section{3 窒素成分の変化}

流出水の水質をTable 2 に、循環比と窒素化合物濃度 の関係を Fig. 2 に示した。最大除去率は循環比 2 でT-N が41.7\%、 $\mathrm{NH}_{4}{ }^{+}-\mathrm{N}$ が62.7\%であった。循環比 2 では硫 黄酸化反応に由来すると考えられる $\mathrm{SO}_{4}{ }^{2-}-\mathrm{S}$ 濃度が最も

Table 1 Characteristics of raw wastewater and influent of the reactor.

\begin{tabular}{|c|c|c|c|c|}
\hline \multirow{2}{*}{ Analysis Item } & \multicolumn{2}{|c|}{ Raw water } & \multicolumn{2}{c|}{ Influent } \\
\cline { 2 - 5 } & Range & Average & Range & Average \\
\hline \hline $\mathrm{pH}(-)$ & $6.4-7.8$ & - & $7.3-8.4$ & - \\
$\mathrm{Color}(\mathrm{U})$ & $\mathrm{ND}$ & $\mathrm{ND}$ & $1833-3350$ & 2455 \\
$\mathrm{BOD}(\mathrm{mg} / l)$ & $1410-12960$ & 5361 & $146-800$ & 375 \\
$\mathrm{CODcr}(\mathrm{mg} / l)$ & $3730-31270$ & 12823 & $865-2404$ & 1538 \\
$\mathrm{~T}-\mathrm{N}(\mathrm{mg} / l)$ & $314-1480$ & 909 & $684-967$ & 806 \\
$\mathrm{NH}_{4}-\mathrm{N}(\mathrm{mg} / l)$ & $174-900$ & 603 & $562-832$ & 711 \\
$\mathrm{NO}_{3}-\mathrm{N}(\mathrm{mg} / l)$ & 0 & 0 & $4.2-5.1$ & 4.6 \\
$\mathrm{NO}_{2}-\mathrm{N}(\mathrm{mg} / l)$ & 0 & 0 & 0 & 0 \\
$\mathrm{~T}-\mathrm{P}(\mathrm{mg} / l)$ & $104-432$ & 292 & $55.9-124.5$ & 78 \\
$\mathrm{PO}_{4}-\mathrm{P}(\mathrm{mg} / l)$ & $30-212$ & 129 & $51.5-84.5$ & 66 \\
$\mathrm{SO}_{4}-\mathrm{S}(\mathrm{mg} / l)$ & $\mathrm{ND}$ & $\mathrm{ND}$ & $10.0-21.5$ & 13 \\
\hline
\end{tabular}


Table 2 Water quality of effluent.

\begin{tabular}{|c|c|c|c|c|c|c|}
\hline \multirow{2}{*}{\multicolumn{2}{|c|}{ Analysis Item }} & \multicolumn{5}{|c|}{ Circulation ratio } \\
\hline & & 0 & 1 & 2 & 4 & 8 \\
\hline $\mathrm{pH}(-)$ & Range & $8.2-8.3$ & $8.3-8.5$ & $7.6-8.1$ & $7.8-8.0$ & $8.2-8.4$ \\
\hline $\begin{array}{c}\text { Color } \\
(\mathrm{U})\end{array}$ & $\begin{array}{l}\text { Range } \\
\text { Average }\end{array}$ & $\begin{array}{c}200-2405 \\
2240.9 \\
\end{array}$ & $\begin{array}{c}2191-2484 \\
2385.2\end{array}$ & $\begin{array}{c}1173-1900 \\
1555.8\end{array}$ & $\begin{array}{c}1670-1717 \\
1684.3\end{array}$ & $\begin{array}{c}1770-2615 \\
2141.6\end{array}$ \\
\hline $\begin{array}{c}\mathrm{BOD} \\
(\mathrm{mg} / \mathrm{l})\end{array}$ & $\begin{array}{l}\text { Range } \\
\text { Average }\end{array}$ & $\begin{array}{c}180-250 \\
200.5 \\
\end{array}$ & $\begin{array}{c}190-290 \\
235.4 \\
\end{array}$ & $\begin{array}{c}54-230 \\
162.1 \\
\end{array}$ & $\begin{array}{c}83-150 \\
107\end{array}$ & $\begin{array}{c}62-280 \\
181.2 \\
\end{array}$ \\
\hline $\begin{array}{l}\text { CODcr } \\
(\mathrm{mg} / \mathrm{l})\end{array}$ & $\begin{array}{l}\text { Range } \\
\text { Average }\end{array}$ & $\begin{array}{c}1000-1307 \\
1141.3\end{array}$ & $\begin{array}{c}937-1111 \\
987.7\end{array}$ & $\begin{array}{c}708-960 \\
820.9\end{array}$ & $\begin{array}{c}710-887 \\
776.6\end{array}$ & $\begin{array}{c}667-1162 \\
909.8\end{array}$ \\
\hline $\begin{array}{c}\mathrm{T}-\mathrm{N} \\
(\mathrm{mg} / \mathrm{l})\end{array}$ & $\begin{array}{l}\text { Range } \\
\text { Average }\end{array}$ & $\begin{array}{c}640.0-794.5 \\
708.1\end{array}$ & $\begin{array}{c}813.0-920.0 \\
858.2\end{array}$ & $\begin{array}{c}400.0-600.0 \\
515.3\end{array}$ & $\begin{array}{c}558.0-570.8 \\
563.7\end{array}$ & $\begin{array}{c}598.7-733.9 \\
675.1\end{array}$ \\
\hline $\begin{array}{l}\mathrm{NH}_{4}-\mathrm{N} \\
(\mathrm{mg} / \mathrm{l})\end{array}$ & $\begin{array}{c}\text { Range } \\
\text { Average }\end{array}$ & $\begin{array}{c}570.0-763.5 \\
657.1\end{array}$ & $\begin{array}{c}720.5-805.0 \\
752.5\end{array}$ & $\begin{array}{c}259.8-460.3 \\
354.2\end{array}$ & $\begin{array}{c}335.6-529.5 \\
397.9\end{array}$ & $\begin{array}{c}455.5-686.0 \\
593.6\end{array}$ \\
\hline $\begin{array}{l}\mathrm{NO}_{3}-\mathrm{N} \\
(\mathrm{mg} / \mathrm{l})\end{array}$ & $\begin{array}{l}\text { Range } \\
\text { Average }\end{array}$ & $\begin{array}{l}4.6 \\
4.6 \\
\end{array}$ & $\begin{array}{c}4.4-6.3 \\
4.9\end{array}$ & $\begin{array}{c}4.6-5.3 \\
4.8\end{array}$ & $\begin{array}{c}4.9-5.1 \\
4.9\end{array}$ & $\begin{array}{c}4.6-5.1 \\
4.8\end{array}$ \\
\hline $\begin{array}{l}\mathrm{NO}_{2}-\mathrm{N} \\
(\mathrm{mg} / \mathrm{l})\end{array}$ & $\begin{array}{c}\text { Range } \\
\text { Average }\end{array}$ & $\begin{array}{c}0-8.0 \\
3.8\end{array}$ & $\begin{array}{c}0-7.0 \\
1.0\end{array}$ & $\begin{array}{c}16.0-155.0 \\
98.1\end{array}$ & $\begin{array}{c}130.0-178.0 \\
147.6\end{array}$ & $\begin{array}{c}0-101.5 \\
57.1\end{array}$ \\
\hline $\begin{array}{c}\mathrm{T}-\mathrm{P} \\
(\mathrm{mg} / \mathrm{l})\end{array}$ & $\begin{array}{l}\text { Range } \\
\text { Average }\end{array}$ & $\begin{array}{c}40.2-55.0 \\
50.8\end{array}$ & $\begin{array}{c}42.3-59.0 \\
49.7\end{array}$ & $\begin{array}{c}40.9-90.0 \\
60.2\end{array}$ & $\begin{array}{c}45.3-54.2 \\
48.5\end{array}$ & $\begin{array}{c}44.4-64.0 \\
55.7\end{array}$ \\
\hline $\begin{array}{l}\mathrm{PO}_{4}-\mathrm{P} \\
(\mathrm{mg} / \mathrm{l})\end{array}$ & $\begin{array}{l}\text { Range } \\
\text { Average }\end{array}$ & $\begin{array}{c}36.0-50.0 \\
39.6 \\
\end{array}$ & $\begin{array}{c}38.5-47.5 \\
43.4 \\
\end{array}$ & $\begin{array}{c}46.0-77.5 \\
59.3 \\
\end{array}$ & $\begin{array}{c}49.0-55.5 \\
52 \\
\end{array}$ & $\begin{array}{c}43.5-52.0 \\
50\end{array}$ \\
\hline $\begin{array}{l}\mathrm{SO}_{4}-\mathrm{S} \\
(\mathrm{mg} / \mathrm{l}) \\
\end{array}$ & $\begin{array}{l}\text { Range } \\
\text { Average }\end{array}$ & $\begin{array}{c}69.0-85.0 \\
74.1 \\
\end{array}$ & $\begin{array}{c}61.5-68.0 \\
65.9 \\
\end{array}$ & $\begin{array}{c}100.0-231.5 \\
156.5\end{array}$ & $\begin{array}{c}136.0-144.0 \\
138.9\end{array}$ & $\begin{array}{c}54.0-149.5 \\
94\end{array}$ \\
\hline
\end{tabular}

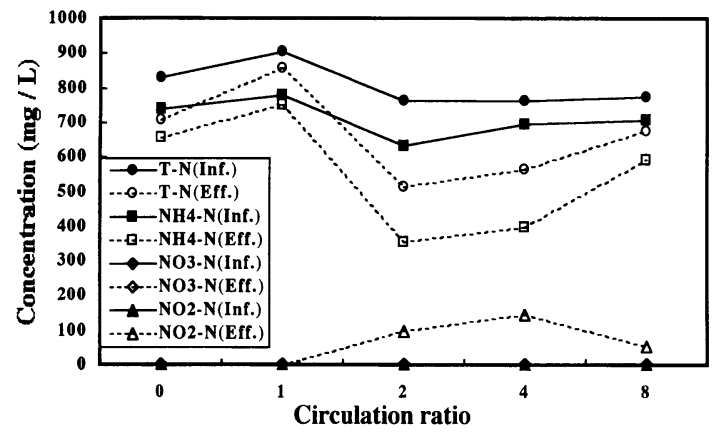

Fig. 2 Influence of circulation ratio on the concentration of nitrogenous compounds.

Symbol : O, T-N (Inf.) ; O, T-N (Eff.) ;

, $\mathrm{NH}_{4}^{+}-\mathrm{N}$ (Inf.) $\square, \mathrm{NH}_{4}^{+}-\mathrm{N}$ (Eff.) :

, $\mathrm{NO}_{3}{ }^{-}-\mathrm{N}$ (Inf.) $; \diamond, \mathrm{NO}_{3}{ }^{-}-\mathrm{N}$ (Eff.)

$\triangle, \mathrm{NO}_{2}^{-}-\mathrm{N}$ (Inf.) $; \triangle, \mathrm{NO}_{2}^{-}-\mathrm{N}$ (Eff.)

高いこと、除去 $\mathrm{BOD}$ 量 (平均 $213 \mathrm{mg} / l$ ) と除去 $\mathrm{TN}$ 量 (平 均 $291 \mathrm{mg} / l)$ との比 $(\triangle \mathrm{BOD} / \triangle \mathrm{T}-\mathrm{N})$ はO.7であり有 機物のみによる脱窒の場合の一般的な BOD必要量であ るBOD/N比 3 に比較してかなり小さく有機物だけによ る脱窒とは考えられないことなどから硫黄脱窒反応の寄 与が推定できる。

$\mathrm{NO}_{3}{ }^{-}-\mathrm{N}$ は循環比と無関係に約 $5 \mathrm{mg} / l$ の低い濃度であ った。これに対して、 $\mathrm{NO}_{2}{ }^{-}-\mathrm{N}$ の濃度は循環比によって
大きく変化し、循環比 2 以上では $100 \mathrm{mg} / l$ 前後の高濃度 の蓄積があったが、1と0では検出されなかった。この 結果は垔硝酸酸化反応が何らかの原因で阻害されていた ことを示唆している。この阻害要因を Anthonisen ら ${ }^{14)}$ の $\mathrm{NH}_{4}{ }^{+}-\mathrm{N}$ おょび $\mathrm{NO}_{2}{ }^{-}-\mathrm{N}$ 濃度と $\mathrm{pH}$ 関係を示した diagramを用いて検討した結果、Fig. 3 に示したように流 入水および流出水の殆どが要硝酸から硝酸への反応が抑 制される0.1mg/ $l$ 以上のFA濃度の範囲 $(4.9-100 \mathrm{mg} / l$, 平均 : $34.9 \mathrm{mg} / l)$ に入っていた。一方、FNAは $0.2 \mathrm{mg} /$ l以下であり、FNAの影響は小さかったと推定される。従 って、FAが亜硝酸酸化の阻害要因であった可能性が高 いといえる。この結果より、今回の実験における $\mathrm{NH}_{4}{ }^{+}-$ $\mathrm{N}$ 濃度と $\mathrm{pH}$ の条件では特に制御を行わなくても亜硝酸 が蓄積することが確認された。

なお、 $\mathrm{NO}_{2}{ }^{-}-\mathrm{N}$ と $\mathrm{SO}_{4}{ }^{2-}-\mathrm{S}$ の生成量が多い場合でも $\mathrm{pH}$ の 低下はあまりなかった。その理由としては、 $\mathrm{S}^{\mathrm{o}}+\mathrm{CaCO}_{3}$ pelletの中の炭酸カルシウムが緩衝効果を発揮したと考 えられた。よって今回用いた硫黄材料は適切な炭酸カル シウム含有率であったといえる。

Thiobacillus denitrificansによる硫黄脱窒反応式と して報告されている式(1)を用いて、 $\mathrm{SO}_{4}{ }^{2 \sim}-\mathrm{S}$ 生産量と脱 窒量との関係を求めた。

$$
1.114 \mathrm{~S}^{\mathrm{o}}+\mathrm{NO}_{3}{ }^{-}+0.699 \mathrm{H}_{2} \mathrm{O}+0.337 \mathrm{CO}_{2}+
$$

$0.0842 \mathrm{HCO}_{3}^{-}+0.0842 \mathrm{NH}_{4}^{+}$ 


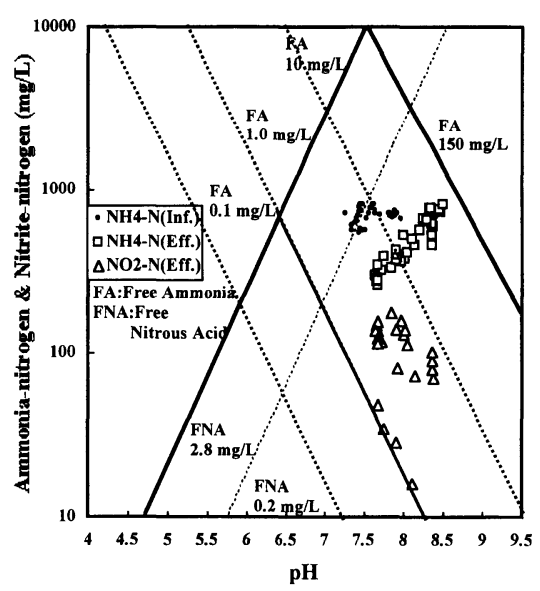

Fig. 3 Estimation of free ammonia(FA) and free nitrous $\operatorname{acid}(\mathrm{FNA})$ concentration in influent and effluent. Symbol :, $\mathrm{NH}_{4}{ }^{+}-\mathrm{N}$ (Inf.) ; $\square, \mathrm{NH}_{4}{ }^{+}-\mathrm{N}$ (Eff.) ; $\triangle, \mathrm{NO}_{2}{ }^{-}-\mathrm{N}(\mathrm{Eff}$.

$\rightarrow \quad 0.0842 \mathrm{C}_{2} \mathrm{H}_{7} \mathrm{NO}_{2}+0.5 \mathrm{~N}_{2}+1.114 \mathrm{SO}_{4}{ }^{2-}$

$$
-\mathrm{S}+1.228 \mathrm{H}^{+}-\cdots-\cdots-\cdots---(1)^{15)}
$$

この式から求められる $\Delta \mathrm{T}-\mathrm{N} / \triangle \mathrm{SO}_{4}{ }^{2-}-\mathrm{S}$ の理論值は 0.43 であり、 $\triangle \mathrm{NO}_{3}{ }^{-}-\mathrm{N} / \triangle \mathrm{SO}_{4}{ }^{2-}-\mathrm{S}$ は0.39である。

また、報告されているエネルギー収得だけを考えた場 合の式は、式(2)であり、式(2)から求められた $\Delta \mathrm{NO}_{3}{ }^{-}-\mathrm{N}$ $/ \triangle \mathrm{SO}_{4}{ }^{2-}-\mathrm{S}$ の理論値は0.53である。

$5 \mathrm{~S}^{\circ}+6 \mathrm{NO}_{3}{ }^{-}+2 \mathrm{H}_{2} \mathrm{O} \rightarrow 3 \mathrm{~N}_{2}+5 \mathrm{SO}_{4}{ }^{2-}+4 \mathrm{H}^{+}$ $-(2)^{16)}$

しかし、亜硝酸からの硫黄脱窒に関して報告されてい る式はなかったので、式(3)を用いて検討した。

$\mathrm{S}^{0}+2 \mathrm{NO}_{2}{ }^{-} \rightarrow \mathrm{N}_{2}+\mathrm{SO}_{4}{ }^{2-}-\cdots-\cdots-\cdots(3)$

式(3)からの $\triangle \mathrm{NO}_{2}{ }^{-}-\mathrm{N} / \triangle \mathrm{SO}_{4}{ }^{2-}-\mathrm{S}$ の理論值は0.88であっ た。

以上の理論値に対して、 $\triangle \mathrm{T}-\mathrm{N} / \triangle \mathrm{SO}_{4}{ }^{2-}-\mathrm{S}$ の実験值 は、循環比 8 で1.29、4 4 で1.56、2 2 で1.86、1 1 で0.82、 0 で1.92であり、理論値よりかなり高いことから、反応 槽内の脱窒には、硫黄以外にBOD も関与したと考えられ る。

一方、 $\triangle \mathrm{BOD}$ の全てが脱窒に使われたと仮定し、さら に脱窒の $\mathrm{BOD} / \mathrm{N}$ 比が $3 \sim 5$ と仮定すると、 $\triangle \mathrm{T}-\mathrm{N} / \triangle$ BODは0.2〜0.33となる。この值は実験值の $\triangle \mathrm{T}-\mathrm{N} / \triangle$ BOD（循環比 8 で0.55、4 4 で0.79、2 で0.45、1 で0.68、 0で0.54）よりかなり小さい值である。従ってBODだけ による脱窒は不可能であり、硫黄脱窒の関与は確実と思 われる。

ただし、硫黄脱窒が硝酸からであるか、亜硝酸からで
あるかについては、上記のようにBODも脱窒に関与し、 また単一反応槽の中で硝化と脱窒が同時に行われるため、 $\triangle \mathrm{T}-\mathrm{N} / \triangle \mathrm{SO}_{4}{ }^{2-}-\mathrm{S}$ などの比から判断することは困難で あった。

通常、硝化過程での律速段階は $\mathrm{NH}_{4}{ }^{+}-\mathrm{N} \rightarrow \mathrm{NO}_{2}{ }^{-}-\mathrm{N}$ であ り、 $\mathrm{NO}_{2}{ }^{-}-\mathrm{N} \rightarrow \mathrm{NO}_{3}{ }^{-}-\mathrm{N}$ の反応は素早く進行し、 $\mathrm{NO}_{2}{ }^{-}-\mathrm{N}$ が蓄積されることはあまり起こらない。また脱窒におい ては、電子供与体の所用量の面から、 $\mathrm{NO}_{2}{ }^{-}-\mathrm{N}$ からの脱 窒が $\mathrm{NO}_{3}{ }^{-}-\mathrm{N}$ からの脱窒より有利であり、 $\mathrm{NO}_{3}{ }^{-}-\mathrm{N} に$ 比較 して $\mathrm{NO}_{2}{ }^{-}-\mathrm{N}$ の脱窒の方が抑制されることは考えにくい。 従って、今回の実験で $\mathrm{NO}_{2}{ }^{-}-\mathrm{N}$ が蓄積したのは、 $\mathrm{NO}_{3}{ }^{-}-\mathrm{N}$ が優占的に脱窒されたためと考えるよりは、硝化が亜硝 酸までしか進まず、しかも脱窒活性が低い条件であった ためと考える方が自然である。

また処理性能を向上するためには、硝化層、硫黄脱窒 層の層厚の上昇といった構造面の改善やHRT、通気量等 の運転条件の最適化を行うことが重要である。

\section{4 着色度の変化}

着色度は循環比 2 のとき、最大 $55 \%$ 減少した。平均脱 色率は循環比 0 では $11.0 \% 、 1$ で8.3\%、2 で30.3\%、 4 で20.1\%、そして 8 で21.0\%であった。

脱色率と各物質との相関を調べた結果、殆どの物質の 変化と脱色率との相関係数が 0.5 以下であるに対して、流 出水の $\mathrm{SO}_{4}{ }^{2-}-\mathrm{S}$ が 0.757 、流出水の $\mathrm{pH}$ が 0.637 であった。硫 黄酸化反応によって $\mathrm{SO}_{4}{ }^{2-}-\mathrm{S}$ が生成され、それに従って $\mathrm{pH}$ も変化したと考えられる。この結果から、硫黄酸化反 応と脱色には緊密な関係のある可能性が示唆された (Fig. 4 )。

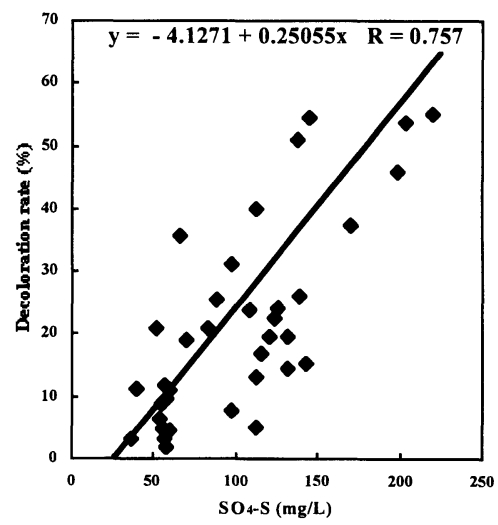

Fig. 4 The relation between decoloration rate and produced sulfate concentration. 
この関係の原因は明らかではないが、(1)硫黄から硫酸 への酸化反応の中間体である亜硫酸の強い還元力によっ て脱色される。(2)硫黄酸化菌によるフミン質の分解によ って脱色する。(3) pelletに含まれている炭酸カルシウム の凝集作用によって脱色される、などの可能性が考えら れる。これらの点については現在実験的に検討中である。

\section{4. まとめ}

上部には好気ゾーン、下部には硫黄を充填した無酸素 ゾーンを設けた反応槽を用いて、嫌気性処理後の音舎污 水の窒素除去を循環比に焦点を置いて検討し、以下の結 果が得られた。

（1）単一反応槽の中で上部の高いDOゾーンと下部の低 いDOゾーンを形成することができた。

(2) 窒素除去率は循環比 2 のとき最も高く、平均は $32.5 \%$ 、最大除去率は $41.7 \%$ であった。

(3) 循環比 2 以上では $\mathrm{NO}_{2}{ }^{-}-\mathrm{N}$ 蓄積が見られたが、 $\mathrm{NO}_{3}{ }^{-}-\mathrm{N}$ はすべての循環比で $5 \mathrm{mg} / l$ 程度と低かった。 流入水および流出水の殆どが亜硝酸から硝酸への反応 が抑制される0. $1 \mathrm{mg} / l$ 以上のFA濃度の範囲 (4.9-100 $\mathrm{mg} / l$, 平均 $: 34.9 \mathrm{mg} / l)$ に入っていたことから FAに よる阻害が亜硝酸蓄積の原因と思われる。

(4) $\mathrm{S}^{\mathrm{o}}+\mathrm{CaCO}_{3}$ pelletに含まれる炭酸カルシウムは、 $\mathrm{pH}$ を高く保つことにより FA濃度を高め、硝化を亜硝酸で に止める効果を発揮したと推定された。

(5) 生成した $\mathrm{SO}_{4}{ }^{2-}-\mathrm{S}$ と脱色率の間で0.757の高い相関 係数が得られ、硫黄酸化反応による脱色の可能性が示 唆された。硫黄酸化反応と脱色との関係については今 後さらに反応解明の研究を行う必要がある。 今回の実験では一槽式の反応槽で硝化・硫黄脱窒・脱 色が可能であることを確認できたので、今後性能向上に ついて検討する予定である。

\section{謝 辞}

本研究は、科学技術振興事業団のSTA Fellowship (1999. 10-2001. 9) によって実施された研究であり、謝意を表 します。また $\mathrm{S}^{\mathrm{o}}+\mathrm{CaCO}_{3}$ pelletを御恵与頂いた東京農業 大学の増島博教授と株式会社ニッチツ、分析等に助言と 協力を頂いた、畜産試験場の羽賀清典先生、住谷啓子さ ん、鈴木一好さん、長田隆さん、和木美代子さんに厚く 御礼申し上げます。

\section{参考文献}

1）羽賀清典：畜産環境対策大事典、17-20，農文協 (1995)

2 ) W. Bae, S. Back, K. Min, J. Jeong, J. Hong, and W. Lee : High strength nitrogen wastewater treatment using short-cut biological nitrogen removal process, 大韓環境工学会' 99 秋季学術研究発表会論文集 (I), 5-6(1995)

3 ) Hellinga, C., Schellen, A. A. J. C., Mulder, J. W., Loosdrecht, M. C. M., and Heijnen, J. J. : The SHARON Process : An Innovative method for nitrogen removal from ammonium-rich waste water, Wat. Sci. Tech., 37(9), 135-142 (1998)

4 ) Anthonisen, Z.H. and Randall, C.W. : The effect of organic compounds on biological phosphorous removal, Water Sci.Technol., 23, 585-594 (1991)

5 ) 橋本奨 : バイオテクノロジー活用の高機能型活性污 泥法、技報堂出版、165-166（1989）

6 ）増島博、矢部环磨、西村岳史、谷田貝敦：硫黄造粒 物を用いた農地排水の脱窒処理、33回日本水環境学 会年会講演集, 256（1999）

7 ) 市来秀之、渡辺輝夫、道宗直昭、増田信幸、河合勝 弘：畜舎排水の紫外線による脱色法及びその装置、 特開平10-085771（1998）

8 ）森達摩、崎元道男、森忠明: 有色廃水の脱色方法、 特開平10-156347（1998）

9 ）和田安弘、村松考人：和歌山市における染料含有排 水への対応、水環境学会誌、20（4）, 16-19（1997）

10）海賀信好：染料含有排水における脱色技術の動向、 水環境学会誌、20 (4), 10-15（1997）

11) Alleman, J.E., Keramida, V., and Pantea-Kiser, L. : Light induced Nitrosomonas inhibition, Water Res. 22, 499-504 (1987)

12）三好康彦: 色度測定方法の現状と今後への対応、水 環境学会誌、20 (4),7-9(1997)

13) Borhnke, B. Diering, B., and Zuckut, S.W. : Costeffective wastewater treatment for removal of organics and nutrients, Water Eng. Manag., 144,1821 (1997)

14) Anthonisen, A.C., Loehr, R.C., Prakasam, T.B.S., and Srinath, E.G. : Inhibition of nitrification by ammonia and nitrous acid, J. Wat. Pollut. Control Fed., 48, 835 - 852 (1976)

15) Bisogni, J.J.Jr. and Driscoll, C.T.Jr. : Denitrification using thiosulfate and sulfide, Jour. Environ. Eng. Div., Proc. ASCE, 103, 593-604 (1977)

16) Roger, Y.S., Michael, D., and Edward A.A. : The microbial world, Prentice-Hall, Inc., USA, 214 (1970)

(受付 2001.2.7)

(受理 2001.6.8) 